\title{
Erratum to: High efficiency of heavy metal re- moval in mine water by limestone
}

\author{
YAO Zhigang ${ }^{1,2^{*}}$, ZHOU Lifa $^{1}$, BAO Zhengyu ${ }^{3}$, GAO Pu${ }^{2}$, and SUN Xingwang ${ }^{4}$ \\ ${ }^{1}$ Key Laboratory of Continental Dynamics, Ministry of Education/Department of Geology, Northwest University, Xi'an 710069, China \\ ${ }^{2}$ School of Petroleum Resources, Xi'an Shiyou University, Xi'an 710065, China \\ ${ }^{3}$ State Key Laboratory of Geological Processes and Mineral Resources, China University of Geosciences, Wuhan 430074, China \\ ${ }^{4}$ Chuankou Oilfield, Yanchang Oilfield Administration Bureau, Shaanxi, Yan'an 768001, China \\ *Corresponding author, E-mail: yzg123-68@163.com
}

Received September 29, 2007; accepted December 14, 2007

(C) Science Press and Institute of Geochemistry, CAS and Springer-Verlag Berlin Heidelberg 2010

Erratum to: Chin.J.Geochem.(2009)28:293-298

DOI: 10.1007/s11631-009-0293-5

In the online version of the article the last name of the first author is misspelled. The correct spelling is "Yao".

The online version of the original article can be found at

http://dx.doi.org/10.1007/s11631-009-0293-5 